\title{
Development of Shock Sensitive Tiny Dummy Robot for Junior High School Rescue Robot Challenge
}

\author{
Kazuo Kawada, Kesuke Iuchi, Keita Murai and Hiroyuki Y. Suzuki \\ Graduate School of Humanities Social Sciences, Hiroshima University, 1-1-1 Kagamiyama \\ Higashi-Hiroshima, Hiroshima 739-8524, Japan \\ E-mail:kawada@hiroshima-u.ac.jp,hiro-suzuki@hiroshima-u.ac.jp
}

\begin{abstract}
Junior High School Rescue Robot Challenge is an annual activity held by Hiroshima University with sponsorship of a construction machinery company. The theme in 2020 was to convey injured people "tenderly" from top of half-demolished building to ground. We developed shock sensitive tiny dummy robot, controlled by M5STACK microcomputer since it rigged with accelerometer. The remote (wired) controlled robots developed by junior high school students conveyed the dummy and evaluated their performances including "tenderness" of the robots using the dummy.
\end{abstract}

Keywords: Rescue Dummy, Robot Evaluation, Technology Education, Junior High School

\section{Introduction}

Robot contest is an attractive activity for both students and instructors in junior high school technology education. Planning, processing, assembling and manipulating robots by themselves make students foster ingenuity and creativity in a great deal. Such experiences can increase interest in today's science and technology developments as well.

A number of robot contests ${ }^{1-3}$ have been held heretofore, in Japan, in which they claimed that those contests have been successful to foster the capacities of invention, logical thinking and creativity in young participants. Those activities, on the other hand, focused on "winning or losing of a game" for evaluation of the robots. Introduction of competition is a good way to arouse incentive in participants' minds, but it also has side effect of narrowing the view on the subject. Any robots contain complexity in them, regardless of the level of the product. They are not machines of single function. We always have to treat the robots as system. Evaluation of robots also, therefore, must be systematic. In the other word, it must be done from various viewpoints. Remind that the guideline for junior high school technology education (stated by Ministry of Education, Culture, Sports, Science and Technology) also claims that we have to deal with humanities in a context of development of technologies. Manufacturing education must be humanity development education as well. Robots of only high performances must not be required, but robots which can consider and cooperate with others will be expected.

In such context, we abandoned the word "Contest" from our robot activity and chose "Challenge" as an alternative. Faculty of Education in Hiroshima University has been holding "Rescue Robot Challenge" from 2014 for junior high school students ${ }^{4}$. It formerly had been named "Rescue Robot Contest" and held since 2003 with the aim of deepening their understanding of social issues and the relationship between people and robots through the creation of robots with an awareness of tenderness to human ${ }^{5}$.

The basic theme of our "Challenge" is human rescue from disastrous conditions. Japan is known as an 
earthquake-prone country. We have faced, in recent years for example, the Kumamoto Earthquake in 2016, the Hokkaido Eastern Iburi Earthquake in 2018, etc. It was natural to desire a rescue robot. In this paper, we are going to describe theme, results and evaluating points of the "Challenge" in 2020.

\section{Challenge Theme in $\mathbf{2 0 2 0}$}

From the era of the "Contest", our activity has used the theme of "quickly rescuing a dummy doll (of $1 / 8$ of real human) from a simulated earthquake site and transport it to a safety zone". Time of rescue has been evaluated as basic data, of course, but ideas for rescuing methods, humanitarian standpoint have been also evaluated. In particular, we have focused on the "tenderness" of the robots to the doll during evacuation.

In 2020's activity, we developed a small shock-sensitive dummy robot. The dummy was put on the remote (wired) controlled robots developed by the middle school students and checks how much shocks and/or vibrations are given during evacuation.

Figure 1 shows the rescue field used in 2020. The robots with dummies are set in the starting area on the roof of the half-demolished building, then start to rescue dummies passing through form Zone A to C. They can choose different rout in Zone B of, i) stairs, ii) a gap with vertical walls and iii) a steep slope. On the ground (Zone C) there are obstacles. The robots finally arrive at the safety zone.

A team consists of 2-5 members of Junior high school students. Every teams firstly give a 4-minute presentation using screen showing about the characteristics of the robot they developed, then followed by a 3-minute rescue activity using real field.

\section{Development of Rescue Dummy}

For simplicity, we used a small tapper box ( $83 \mathrm{~mm}$ in length, $83 \mathrm{~mm}$ in width, and $45 \mathrm{~mm}$ in height) as dummy's body (Fig. 2), although there are not protrudes of legs, arms or a head. We chose a microcomputer module of M5STACK (Fig. 3) as controller since it equipped with accelerometers. Gross weight of the dummy was $81 \mathrm{~g}$.

We set thresholds of the accelerometer of $\pm 1.5 \mathrm{~g}\left[\mathrm{~m} / \mathrm{s}^{2}\right]$ in two directions of $\mathrm{X}$ and $\mathrm{Y}$. When the dummy got two acceleration of threshold or more, LCD (Liquid Crystal

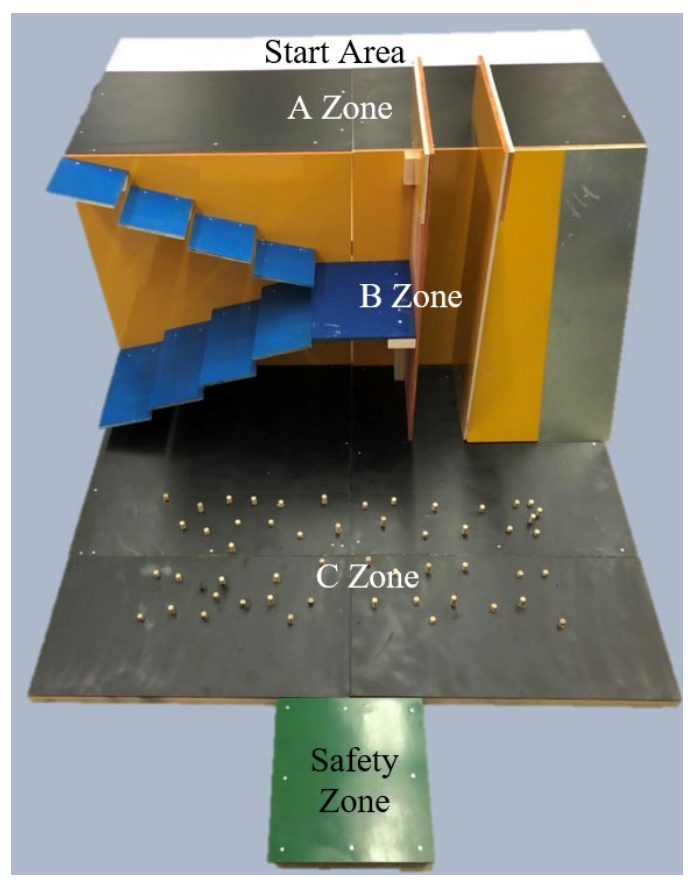

Fig.1 Rescue Field.

Display) of the M5STACK turns red and emits a warning sound. Introduction of the dummy equipped with accelerometer made possible to evaluate more precisely the degree of tenderness of the robot to the dummy.

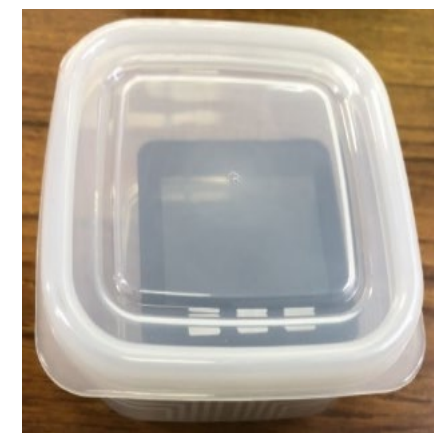

Fig.2 Rescue Dummy with M5STACK.

\section{Result of "Challenge" and Evaluation}

The $6^{\text {th }}$ Rescue Robot Challenge in 2020 were held on Feb. 16th, 2020 (still in 2019 as fiscal year). A total of 11 teams were participated. The points they got are summarized in Table 1. Performances of the robots are evaluated from two viewpoints of, i) goal points and ii) tenderness points. Maximum points of each viewpoint are 20 , so that the maximum total points are 40 . For the goal points, if the robot conveys the dummy to the safety 

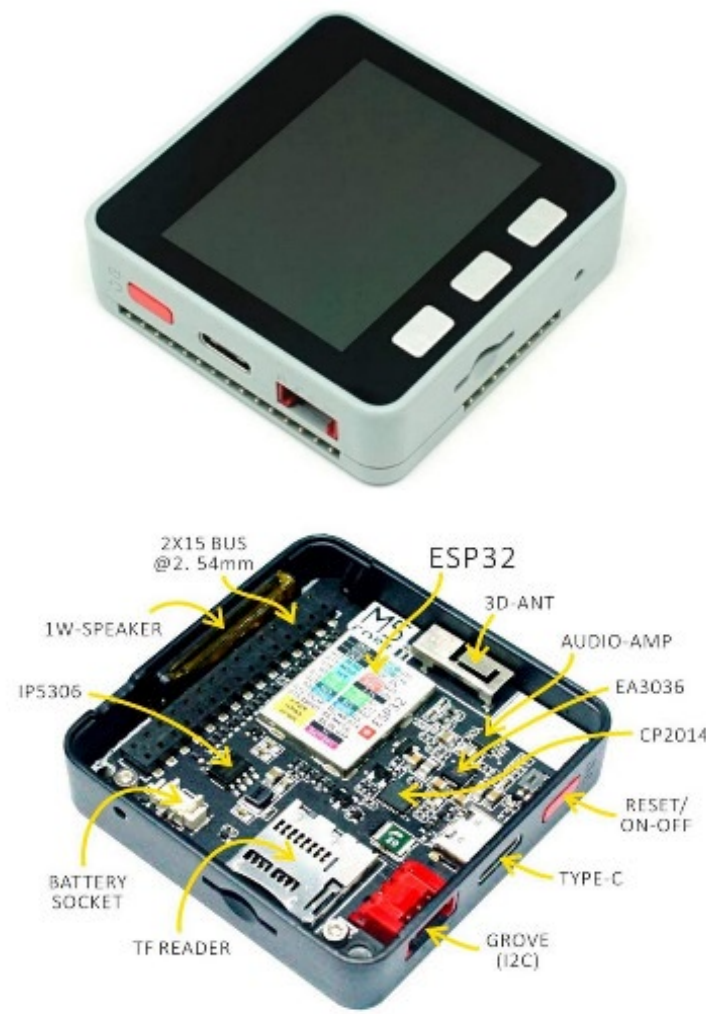

Fig.3 M5STACK with Accelerometer.

zone in 3 minutes without dropping the dummy, it gets 20 points. The goal points are decreased according to degree of problems happened during the rescue activity. For the tenderness points, 20 points are given if no warning sound is made, 15 points for 1-3 times of warning, 10 points for 4-6 warnings, 5 points for 7-9 warnings, and 0 points if the warning surpasses 10 times. Let's see an example. Rescue robot $\mathrm{C}$ is shown in Fig.3. Robot $\mathrm{C}$ was succeeded to transport the dummy to the safety zone without dropping the dummy, so that it got goal point of 20 . On the other hand, the robot $\mathrm{C}$ gave 14 to 19 shocks to the dummy, therefore the tenderness points were decreased much. This robot was using magnets to slowly descend the steel slope in zone B. Their trials were successful during practices. But unluckily, the magnet fell off from the steel slope in final performance, resulting in a big shock to the dummy.

In contrast, the rescue robot $\mathrm{G}$ (Fig. 4) could transport the dummy without giving shocks. This robot used a pantograph mechanism to descend between the gap of two walls in Zone B.
Another interesting idea was found in the Robot H (Fig. 5). It used crawlers for traveling the stairs in Zone B, which result in a speedy transportation of the dummy to the goal. Although it gave several shocks to dummy, the number and degree of the shocks were much less than other robots which chose the stairs in Zone B. It had ingeniously attached long arms in front and behind the body, by which the robot could prevent to stagger by manipulating the arms.

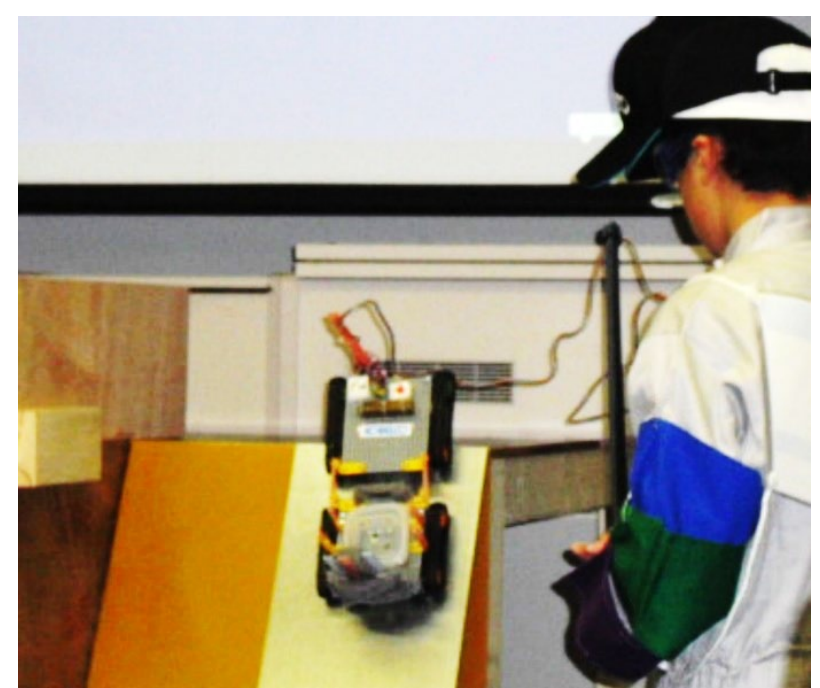

Fig.3 Rescue Robot C.

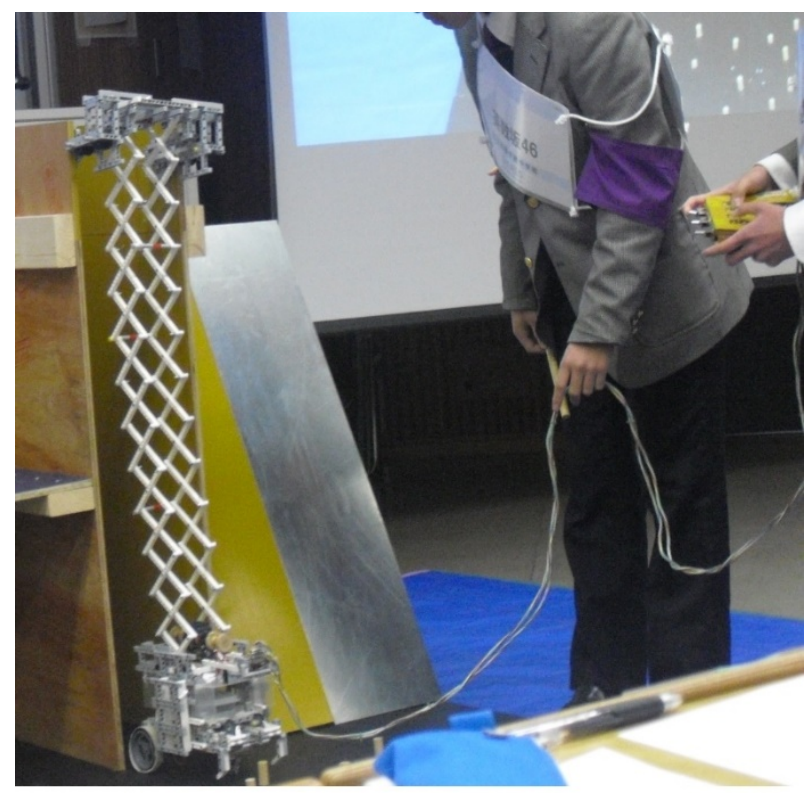

Fig.4 Rescue Robot G. 
Table 1. Goal points and tenderness points for each rescue robot.

\begin{tabular}{|c|c|c|c|c|c|c|c|c|c|c|c|}
\hline $\begin{array}{c}\text { Rescue } \\
\text { robot }\end{array}$ & $\mathrm{A}$ & $\mathrm{B}$ & $\mathrm{C}$ & $\mathrm{D}$ & $\mathrm{E}$ & $\mathrm{F}$ & $\mathrm{G}$ & $\mathrm{H}$ & $\mathrm{I}$ & $\mathrm{J}$ & $\mathrm{K}$ \\
\hline $\begin{array}{c}\text { Goal } \\
\text { points }\end{array}$ & 0 & 0 & 20 & 0 & 0 & 0 & 20 & 20 & 20 & 0 & 0 \\
\hline $\begin{array}{c}\text { Tenderness } \\
\text { points }\end{array}$ & 20 & 15 & 5 & 20 & 20 & 0 & 20 & 15 & 15 & 20 & 20 \\
\hline $\begin{array}{c}\text { Total } \\
\text { points }\end{array}$ & 20 & 15 & 25 & 20 & 20 & 0 & 40 & 35 & 35 & 20 & 20 \\
\hline
\end{tabular}

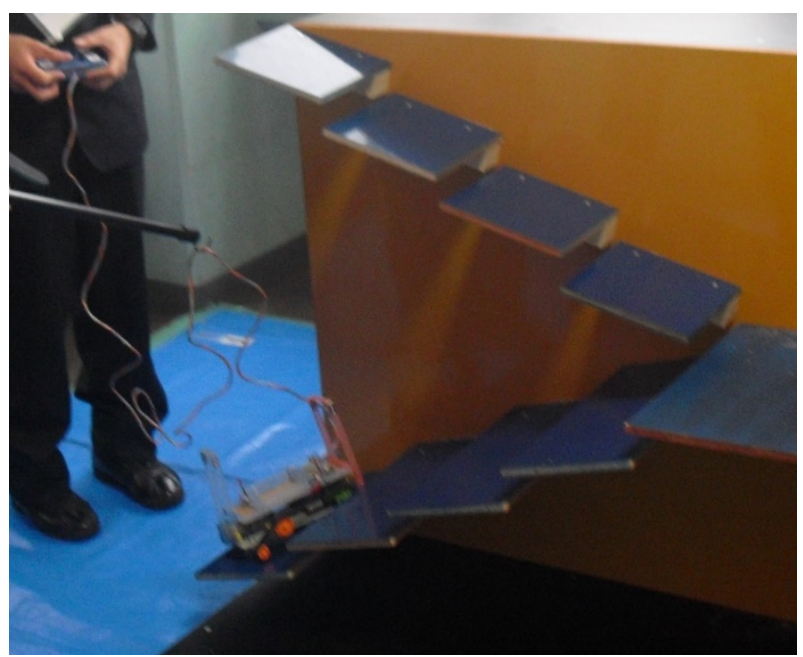

Fig.5 Rescue Robot H.

\section{Discussions}

The 11 rescue robots can be classified according to descending rout in Zone B. Robots of type 1 chose the gap between two walls. Six robots of A, B, E, G, I, and J chose this way. Type 2, four robots $\mathrm{D}, \mathrm{F}, \mathrm{H}$, and $\mathrm{K}$ chose the stairs. Only the robot $\mathrm{C}$ was classified to Type 3, descended a steel slope using a magnet, as we explained in previous section.

The average goal points of Type 1, Type 2, and Type 3 were 6.67 points, 5 points, and 20 points, respectively, indicating that the Type 3 had higher manipulability during transportation in Zone B. On the other hand, the mean of tenderness points for Type 1, Type 2 and Type 3 were 18.33, 13.75 and 5 points. Comparison of the points made clear that the robots of the Type 1 had higher stability during transportation in Zone B. Nonetheless, there are no considerable differences in averages of the total points between Type 1, Type 2, and Type 3, which were $25,18.75$, and 25 points, respectively. These results may indicate that the shortcoming of evaluation from single factor. As we mentioned before, the robots essentially contain "complexity" in their design, mechanism, manipulating manner, and so on, therefore their performances also must be evaluated from various aspects.

\section{Conclusions}

We developed a dummy robot for "Rescue Robot Challenge in 2020". The dummy was sensible to shocks during rescue transportation. Introduction of shock sensible dummy made possible to evaluate quantitatively the "tenderness" of the robots developed by the middle school teams. Adding evaluation factors can improve the correctness of evaluation of robot performances.

\section{References}

1. C. Kasuga, An Analysis of Contesting Robots - Micro Mouse and Sumo Robots, JRM, 10(1), 1998, pp. 22-26.

2. M. Asada, RoboCup-97, JRM, 10(1), 1998, pp. 30-33.

3. T. Yamamoto, T. Ichikawa and S. Fujisawa, A Consideration on Rescue Robot Contest from Viewpoint of Technology Education, JRM, 15(5), 2003, pp. 516-520.

4. K. Okamoto, Y. Shoda, T. Ueno, K. Kawada and M. Nagamatsu, An Approach to 1st Rescue Robot Challenge for Junior High-Shool Students -Present Conditions and Problems-, Technology Education, 6, 2016, pp. 8-15. (in Japanese)

5. K. Kawada, M. Nagamatsu and Toru Yamamoto, A Practice of Rescue Roboto Contest in Junior High School, J.of JSEE, 58-2, 2010, pp. 33-39. (in Japanese) 